\title{
Functions and inter-relationships of operating agencies in policy implementation from a viable system perspective
}

\begin{abstract}
Existence of supporting entities and their cohesive operations are important elements in industry development policy undertaken in emerging economies, which are characterized by heavy government interventions and involved many agencies and institutions. One of the models that emphasizes on cohesiveness as a precondition for viability is the viable system model (VSM). In this study, we adopt the VSM in combination with theories of innovation and innovation system as our conceptual framework to describe and explain the functions and relational structure that exist among agencies/institutions and that of the agencies with their environment elements within one policy level system implementation. We select a biotechnology industry development policy for our analysis, the implementation of which has been designated as a strategic vehicle to support the economic development goals of an emerging economy. The findings, which generate a model of the policy-level system implementation, explain the operating agencies' functions and their inter-relationships. The emergent model provides policy makers and implementers recommendations for improvements, as well as offers future researchers potential for comparison between existing performance of a policy implementation against its expected performance targets. The study concludes that the biotechnology industry development is an effort by the Malaysian government to institutionalize biotechnology businesses and industry. The perspective of systems thinking, in combination with theories of institutionalization, innovation and innovation system, provide important foundations in explaining technology-based industry development. All these findings highlight that the knowledge gain in explaining and interpreting the problem in focus is worthwhile, although the use of VSM as a research tool demands considerable efforts.
\end{abstract}

Keyword: Biotechnology; Viable system model; Systems perspective; Industry development; Innovation; Innovation system; Institutionalization 